\title{
Genetic differentiation and phylogeography of Mediterranean- North Eastern Atlantic blue shark (Prionace glauca, L. 1758) using mitochondrial DNA: panmixia or complex stock structure?
}

Agostino Leone ${ }^{\text {Corresp.., }}{ }^{1}$, Ilenia Urso ${ }^{1}$, Dimitrios Damalas ${ }^{2}$, Jann Martinsohn ${ }^{2}$, Antonella Zanzi ${ }^{2}$, Stefano Mariani $^{3}$, Emilio Sperone ${ }^{4}$, Primo Micarelli ${ }^{5}$, Fulvio Garibaldi ${ }^{6}$, Persefoni Megalofonou ${ }^{7}$, Luca Bargelloni ${ }^{8}$ , Rafaella Franch ${ }^{8}$, David Macias ${ }^{9}$, Paulo Prodöhl ${ }^{10}$, Séan Fitzpatrick ${ }^{10}$, Marco Stagioni ${ }^{11}$, Fausto Tinti ${ }^{1}$, Alessia Cariani ${ }^{1}$

1 Department of Biological, Geological \& Environmental Sciences (BiGeA), Laboratory of Genetics \& Genomics of Marine Resources and Environment (GenoDREAM), University of Bologna, Ravenna, Italy

2 Joint Research Centre (JRC), Directorate D - Sustainable Resources, Unit D2 - Water and Marine Resources, European Commission, Ispra, Italy

3 School of Environment \& Life Sciences, University of Salford, Salford, Greater Manchester, United Kingdom

4 Department of Biology, Ecology and Earth Science (DiBEST), University of Calabria, Arcavacata di Rende, Italy

5 Sharks Research Center, Aquarium Mondo Marino, Massa Marittima, Italy

6 Department of Earth, Environment and Life Sciences, University of Genova, Genova, Italy

7 Department of Biology, National and Kapodistrian University of Athens, Ilissia, Greece

8 Department of Comparative Biomedicine and Food Science, University of Padova, Legnaro, Italy

9 Centro Oceanográfico de Málaga, Instituto Español de Oceanografía, Málaga, Spain

10 School of Biological Sciences, Queen's University, Institute for Global Food Security, Belfast, United Kingdom

11 Department of Biological, Geological \& Environmental Sciences, Marine Biology \& Fisheries Laboratory, University of Bologna, Fano, Italy

Corresponding Author: Agostino Leone

Email address: agostino.leone2@unibo.it

Background. The blue shark (Prionace glauca, Linnaeus 1758) is one of the most abundant epipelagic shark inhabiting all the oceans except the poles, including the Mediterranean Sea, but genetic structure has not been confirmed at basin and interoceanic distances. Past tagging programs in the Atlantic Ocean failed to find evidence of migration of blue sharks between the Mediterranean and the adjacent Atlantic, despite the extreme vagility of the species. Despite the high rate of by-catch in the Mediterranean basin, to date no genetic study on Mediterranean blue shark was carried out, which constitutes a significant knowledge gap, considering that this population is classified as "Critically Endangered", unlike its open-ocean counterpart. Methods. Blue shark phylogeography and demography in the Mediterranean Sea and North-Eastern Atlantic Ocean were inferred using two mitochondrial genes (Cytb and control region) amplified from 207 and 170 individuals respectively, collected from six localities across the Mediterranean and two from the North-Eastern Atlantic. Results. Although no obvious pattern of geographical differentiation was apparent from the haplotype network, Фst analyses indicated significant genetic structure among four geographical groups. 
Demographic analyses suggest that these populations have experienced a constant population expansion in the last 0.4-0.1 million of years. Discussion. The weak, but significant, differences in Mediterranean and adjacent North-eastern Atlantic blue sharks revealed a complex phylogeographic structure, which appears to reject the assumption of panmixia across the study area, but also supports a certain degree of population connectivity across the Strait of Gibraltar, despite the lack of evidence of migratory movements observed by tagging data. Analyses of spatial genetic structure in relation to sex-ratio and size could indicate some level of sex/stage biased migratory behaviour. 


\title{
Genetic differentiation and phylogeography of Mediterranean-North Eastern Atlantic blue shark (Prionace glauca, L. 1758) using mitochondrial DNA: panmixia or complex stock structure?
}

\author{
Agostino Leone ${ }^{1 * c o r r}$, Ilenia Urso ${ }^{1 *}$, Dimitrios Damalas ${ }^{2}$, Jann Martinsohn ${ }^{2}$, Antonella Zanzi ${ }^{2}$, Stefano \\ Mariani $^{3}$, Emilio Sperone ${ }^{4}$, Primo Micarelli ${ }^{5}$, Fulvio Garibaldi ${ }^{6}$, Persefoni Megalofonou ${ }^{7}$, Luca \\ Bargelloni $^{8}$, Rafaella Franch ${ }^{8}$, David Macias ${ }^{9}$, Paulo Prodöhl ${ }^{10}$, Séan Fitzpatrick ${ }^{10}$, Marco Stagioni ${ }^{11}$, \\ Fausto Tinti ${ }^{1}$, Alessia Cariani ${ }^{1}$
}

\author{
${ }^{1}$ Department of Biological, Geological \& Environmental Sciences (BiGeA), Laboratory of Genetics \& Genomics of \\ Marine Resources and Environment (GenoDREAM), University of Bologna, Ravenna, Italy \\ ${ }^{2}$ Joint Research Centre (JRC), Directorate D - Sustainable Resources, Unit D2 - Water and Marine Resources, \\ European Commission, Ispra, Italy \\ ${ }^{3}$ School of Environment \& Life Sciences, University of Salford, Salford, Greater Manchester, United Kingdom \\ ${ }^{4}$ Department of Biology, Ecology and Earth Science (DiBEST), University of Calabria, Arcavacata di Rende, Italy \\ ${ }^{5}$ Sharks Research Center, Aquarium Mondo Marino, Massa Marittima, Italy \\ ${ }^{6}$ Department of Earth, Environment and Life Sciences, University of Genova, Genova, Italy \\ ${ }^{7}$ Department of Biology, National and Kapodistrian University of Athens, Ilissia, Greece \\ ${ }^{8}$ Department of Comparative Biomedicine and Food Science, University of Padova, Legnaro, Italy \\ ${ }^{9}$ Centro Oceanográfico de Málaga, Instituto Español de Oceanografía, Málaga, Spain \\ ${ }^{10}$ School of Biological Sciences, Queen's University, Institute for Global Food Security, Belfast, United Kingdom \\ ${ }^{11}$ Department of Biological, Geological \& Environmental Sciences, Marine Biology \& Fisheries Laboratory, \\ University of Bologna, Fano, Italy \\ corr: corresponding author \\ *These authors contributed equally to this work
}

\begin{abstract}
Background. The blue shark (Prionace glauca, Linnaeus 1758) is one of the most abundant epipelagic shark inhabiting all the oceans except the poles, including the Mediterranean Sea, but genetic structure has not been confirmed at basin and interoceanic distances. Past tagging programs in the Atlantic Ocean failed to find evidence of migration of blue sharks between the Mediterranean and the adjacent Atlantic, despite the extreme vagility of the species. Despite the high rate of by-catch in the Mediterranean basin, to date no genetic study on Mediterranean blue shark was carried out, which constitutes a significant knowledge gap, considering that this population is classified as "Critically Endangered", unlike its open-ocean counterpart.

Methods. Blue shark phylogeography and demography in the Mediterranean Sea and NorthEastern Atlantic Ocean were inferred using two mitochondrial genes (Cytb and control region) amplified from 207 and 170 individuals respectively, collected from six localities across the Mediterranean and two from the North-Eastern Atlantic. Results. Although no obvious pattern of geographical differentiation was apparent from the haplotype network, Фst analyses indicated significant genetic structure among four geographical groups. Demographic analyses suggest that these populations have experienced a constant population expansion in the last $0.4-0.1$ million of years.

Discussion. The weak, but significant, differences in Mediterranean and adjacent North-eastern Atlantic blue sharks revealed a complex phylogeographic structure, which appears to reject the assumption of panmixia across the study area, but also supports a certain degree of population connectivity across the Strait of Gibraltar, despite the lack of evidence of migratory movements observed by tagging data. Analyses of spatial genetic structure in relation to sex-ratio and size could indicate some level of sex/stage biased migratory behaviour.
\end{abstract}




\section{INTRODUCTION}

2 The blue shark (Prionace glauca, Linnaeus 1758; BS henceforth) is one of the most abundant

3 epipelagic sharks that is found in all oceans from $60^{\circ} \mathrm{N}$ to $50^{\circ} \mathrm{S}$ (Compagno, 1984). Blue sharks

4 are rarely targeted by commercial fishing, but feature prominently as by-catch of fisheries

5 targeting large pelagic fish, especially swordfish and tuna longlines (Fowler et al., 2005). BS

6 populations trend data are available only for a part of the geographic range and stock assessments

7 are highly uncertain (Dulvy et al., 2014; Coelho et al., 2017); due to the huge amount of by-

8 caught BS (approx. 20 million per annum, Stevens et al., 2009), the species has being categorized

9 worldwide as "Near Threatened" in the IUCN Red List (Stevens, 2009). Based on recent assessment (ICCAT, 2015), the North Atlantic stock is unlikely to be currently overfished. The Mediterranean BS, on the other hand, is estimated to have undergone a $90 \%$ decline over three generations, primarily due to overfishing (Ferretti et al., 2008), and is now categorized as the increasing commercial value of the species (Megalofonou et al., 2005) and the persistent issue of the global trade in shark fin products, of which BS is the main component (Clarke et al., 2006), a more explicit management is needed for this species, which should be underpinned by robust knowledge of its population structure.

In the Atlantic, BS is distributed from Canada to Argentina, on the western side, and from Norway to South Africa on the eastern side, including the Mediterranean Sea (Compagno, 1984). The population structure and dynamics of Atlantic BS is still poorly known, despite several longterm tagging studies, which revealed extensive movements of BS tagged in the western side of the North Atlantic (henceforth NA), with well documented eastward trans-Atlantic migrations (Kohler et al. 1998, 2002; Kohler \& Turner, 2008; Vandeperre et al., 2014). Sexual segregation was also evident, with a concentration of mature females in more temperate waters of the northernmost NA, and immature males predominant in the southernmost NA (Sampaio da Costa, 2013). Mature BS of both sexes seemed to be distributed in the southern part of NA, while immature individuals of both sexes and sub-adult females are usually distributed in the northern areas (Kohler et al., 2002). Conversely, a prevalent occurrence of immature juveniles is reported in the Mediterranean Sea (Megalofonou et al., 2009; Kohler et al., 2002). A significant genetic 
31 those from South Africa was detected by Sampaio da Costa (2013) from mitochondrial and nuclear marker variation. Their finding indicated a deeper separation between the northern and the southern NA nurseries and supported a male philopatry behaviour to mating areas exclusively contributing to a single nursery ground. Contradictorily, a recent genetic survey (Verissimo et al., 2017) carried out on the same dataset (i.e., young-of-year and $<2$ years juveniles) collected from the same nurseries, enriched with more samples from different areas (i.e. coasts of Brazil), and using the same type of markers, showed a lack of spatio-temporal genetic differentiation, suggesting the presence of a panmictic population in the whole Atlantic.

To date, no genetic data are available for the Mediterranean BS population and population structure and dynamics of BS in the Mediterranean are presently inferred only by AtlanticMediterranean integrated tagging studies and fishing data assessments (Kohler et al., 1998, 2002; Ferretti et al., 2008; Kohler \& Turner, 2008; Megalofonou et al., 2009).

Irrespective of the small recapture rate (out of the 91,450 BS specimens tagged in the north western Atlantic, only 5.9\% were recaptured), extensive tag-recapture surveys carried out from 1962 to 2000, indicated that North Atlantic BS form a single stock and that trans-Atlantic migratory movements were quite frequent, likely favoured by the oceanic current system (Kohler et al., 2002). Focusing on the Atlantic-Mediterranean connectivity, the reproductive migratory movements of Atlantic BS towards Mediterranean and the degree of population connectivity between the two areas are still unknown, because only one adult BS male tagged in the northwestern Atlantic and one sub adult female tagged in the North-Eastern Atlantic were recaptured in the Mediterranean (Kohler et al., 2002). The large majority of BS tagged in the Mediterranean Sea were immature and remained in the tagging area, with the only exception of a subadult female that moved a short distance to the adjacent north-eastern Atlantic area. Most of the BS caught in the Mediterranean (99\% and 98\% for males and females, respectively) are immature, indicating that the Mediterranean BS stock consists primarily of small immature BS of both sexes, with a sex-ratio skewed toward females or males, depending on different geographical areas (Kohler et al., 2002; Megalofonou et al., 2009). A high number of pregnant females was observed in the Adriatic, North Ionian Sea and Ligurian Sea, suggesting potential nursery grounds for BS (Megalofonou et al., 2009; Garibaldi, 2017 pers.comm.). On the other hand, the adjacent South-Eastern North Atlantic BS was prevalently composed by primarily mature individuals of both sexes with male-based sex ratio.

62 The primary aims of this study is to test the null hypothesis of panmixia between North Atlantic and Mediterranean BS, by comparing the mtDNA genetic variation of two gene regions, the 
64 control region (CR) and the Cytochrome b (Cytb) among four population samples collected in the

65 North-Eastern and South-Eastern North Atlantic and in the Western and Eastern Mediterranean.

66 Given the female philopatry observed in other carcharhiniformes (Mourier \& Planes, 2013; Tillet

67 et al, 2012), mtDNA markers are likely to be useful to spot localised groups due to site-fidelity.

68 Accordingly, this work aims to provide further and needed data on matrilineal genetic structure,

69 female philopatry and demography of Mediterranean BS. These, previously lacking, data will

70 contribute to a better understanding and inclusion of the Mediterranean BS dynamics in the wider

71 North Atlantic population model, to improve assessment and management of BS stocks in the 72 area.

73

74

75

76

77

\section{MATHERIAL AND METHODS}

\section{Blue shark sampling}

Sampling was carried out between 2003 and 2016 and tissue specimens and individual data were collected by means of commercial fishermen and scientific surveys. Mediterranean BS were collected from multiple locations in the Eastern (Central Adriatic, CADR, 21; Ionian Sea, IONI, 15; Aegean Sea and Levantine Sea, AEGE, 20) and Western areas (South Tyrrhenian, TYRR, 10; Ligurian Sea, LIGU, 57; Balearic Islands, BALE, 42). North Atlantic BS were caught from the North Eastern Atlantic Ocean off the coasts of Portugal (SNEATL, 33) and Celtic Sea (NNEATL, 16) (Fig. 1). A total of $214 \mathrm{BS}$ individuals were collected $(\mathrm{N}=91$ males, $\mathrm{N}=101$ females and $\mathrm{N}$ $=22$ unsexed) (Tab. S1). The BS individuals were grouped according the Total Length (TL) in three size categories (Pratt, 1979; Vandeperre et al., 2014): juveniles (J, TL $\leq 120 \mathrm{~cm}$ ), young (Y, $\mathrm{TL}=120-180 \mathrm{~cm})$ and large $(\mathrm{L}, \mathrm{TL} \geq 180 \mathrm{~cm})$.

A unique and transparent sampling documentation tool was developed within the project, in order to render data public. This tool can be used by everyone as an interactive map visiting the website https://fishreg.jrc.ec.europa.eu/web/medbluesgen/sampling-data

\section{Molecular methods}

Individual fin clips or skeletal muscle tissue samples were collected and preserved in $96 \%$ ethanol and kept at $-20^{\circ} \mathrm{C}$ until laboratory analyses. DNA extraction was carried out using the Invisorb® Spin Tissue Kit, Invitek (C STRATEC Molecular) and the Wizard® Genomic DNA Purification Kit, Promega kits, following the manufacturers' protocols.

Species-specific primer pairs for the amplification of the mitochondrial control region (CR) and cytochrome b (Cytb) genes were designed. Homologous complete CR and Cytb sequences of 
95 Prionace glauca available in GenBank were retrieved and aligned using ClusterW algorithm 96 implemented in MEGA ver.7.0 (Tamura et al., 2013). Primer pairs were designed using the online 97 software PRIMER3 (ver.0.4.0) (Untergasser et al., 2012), minimizing the propensity of oligos to 98 form hairpins or dimers or to hybridize or prime from unintended sites in the full mitochondrial 99 BS genome (Acc. Num. NC_022819, Chen et al., 2013).

100 The designed primer pairs (control region: CR-Blues-F 5'AAACACATCAGGGGAAGGAG3', 101 CR-Blues-R 5'CATCTTAGCATCTTCAGTGCC3'; Cytochrome-b: Cytb-Blues-F 5' 102 TCCTCACAGGACTCTTCCTAGC3', Cytb-Blues-R 5'GTCGAAAGATGGTGCTTCGT3') were 103 tested using a temperature gradient to identify the most suitable melting temperatures $\left(\mathrm{T}_{\mathrm{m}}=\right.$ from $10450^{\circ} \mathrm{C}$ to $60^{\circ} \mathrm{C}$ ) according to PCR cycling conditions described by Ovenden et al. (2009).

105 Once the optimal melting temperature was identified, the PCR thermal profile was adjusted and 106 the PCR reactions were performed for both markers in a final volume of $50 \mu \mathrm{L}$ containing 31.75 $107 \mu \mathrm{L}$ of distilled sterile $\mathrm{H}_{2} \mathrm{O}, 8 \mu \mathrm{L}$ of Buffer $10 \mathrm{x}$ (Tris- $\mathrm{HCl}$; final $\left.1 \mathrm{X}\right), 3 \mu \mathrm{L}$ of $\mathrm{MgCl}_{2}(25 \mathrm{mM}$; final $1081.5 \mathrm{mM}), 2 \mu \mathrm{L}$ of dNTPs $(10 \mathrm{mM}$; final $0.37 \mathrm{mM}), 2.5 \mu \mathrm{L}(10 \mu \mathrm{M}$; final $0.46 \mu \mathrm{M})$ of each primer, $1090.25 \mu \mathrm{L}(5 \mathrm{U} / \mu \mathrm{L}$; final $1.5 \mathrm{U})$ of Taq polymerase and $2 \mu \mathrm{L}$ of template DNA(10-20ng). The 110 temperature profile included an initial denaturation at $94^{\circ} \mathrm{C}$ for $2 \mathrm{~min}$, followed by 35 cycles of 111 denaturation at $94^{\circ} \mathrm{C}$ for $30 \mathrm{~s}$, annealing at $60^{\circ} \mathrm{C}$ for $30 \mathrm{~s}$, elongation at $72^{\circ} \mathrm{C}$ for $30 \mathrm{~s}$ and a final 112 elongation step at $72^{\circ} \mathrm{C}$ for $5 \mathrm{~min}$. PCR amplicons were sequenced using the external service 113 provider MACROGEN® Europe.

\section{Data analysis}

115 The CR and Cytb nucleotide sequences obtained were validated with the homologous gene 116 sequences deposited in the GenBank with the BLASTn search implemented in the NCBI website

117 (Altschul et al., 1990), and aligned using the ClusterW algorithm implemented in MEGA ver.7.0 118 (Tamura et al., 2013). When aligned to the complete BS mitochondrial genome, Cytb sequences mapped from nucleotide position 14,530 to 15,291 and CR from 15,651 to 16,397.

120 Given the high potential of geographical dispersal of the species, sequence data were grouped 121 according to the four geographical areas: EMED, WMED, SNEATL and NNEATL (Fig. 1). The 122 software DNAsp v.5.10.01 (Librado \& Rozas, 2009) was used to assess the genetic diversity 123 parameters at both markers: the number of haplotypes $(N h)$, the number of polymorphic sites $(S)$, 124 the haplotype $(h)$ and nucleotide diversity $(\pi)$ with associated standard deviation (stdev). 
125 Haplotype relationships were inferred using the dnaml program of the PHYLIP package version

1263.6 (Felsenstein, 1989; Felsenstein, 2005) implemented in the software program HaploViewer

127 (http://www.cibiv.at/ greg/haploviewer).

128 Partition of molecular variance and its significance was estimated with the AMOVA(Excoffier et 129 al., 1992) implemented in Arlequin ver 3.5.2.2 software (Excoffier \& Lischer, 2010), testing four 130 alternative groupings of geographical sampling locations (1: no groups; 2 : NNEATL+SNEATL vs WMED+EMED; 3: NNEATL+SNEATL vs WMED vs EMED; 4: NNEATL vs SNEATL vs WMED vs EMED). Haplotype frequencies and pairwise $\Phi_{\mathrm{ST}}$ with the associated p-values were calculated using the software Arlequin ver 3.5.2.2 (Excoffier \& Lischer, 2010) after 20,000 permutations, setting up a $\alpha=0.05$ significance threshold level.

Demographic history was investigated using the mismatch distribution as implemented in the DNAsp software (Librado \& Rozas, 2009).

137 Furthermore, historical demographic trend of the four groups was investigated using Bayesian Skyline Plot (BSP) analysis implemented in the software BEAST v.1.8.2 (Drummond et al., 2005; 2012), using the best evolutionary models for both Cytb and CR markers inferred using JModelTest 2.1.1 (Darriba et al., 2012), and the average mutation rate for sharks, $0.62 \%$ and 0.31\% for CR and Cytb respectively (Martin and Palumbi, 1993; Galván-Tiradoa et al., 2013). The same software and parameters, with associate software TreeAnnotator and FigTree, were used to define the phylogeny of the Mediterranean and Eastern Atlantic BS populations.

\section{RESULTS}

145 Among sexed individuals $(\mathrm{N}=192$; Table $\mathrm{S} 1)$, BS females significantly outnumbered males in the NA samples (sex-ratio $0.34, \chi^{2}$ test: $10.256 \mathrm{P}_{2 \text { tail }}=0.001 ; \mathrm{P}_{1 \text { tail }}=0$, d.f. 1 ) while in the two Mediterranean BS groups a weak and not significant predominance of males was observed (WMED: $1.19, \chi^{2}$ test: $0.786 \mathrm{P}_{2 \text { tail }}=0.375 ; \mathrm{P}_{1 \text { tail }}=0.188$, d.f. 1 ; EMED: $1.09, \chi^{2}$ test: $0.087 \mathrm{P}_{2 \text { tail }}=$ 0.768; $\mathrm{P}_{1 \text { tail }}=0.384$, d.f. 1). Sized BS $(\mathrm{N}=209)$ were composed by 63 juvenile, 82 young and 64 large individuals (Table S1). In the NA and WMED the young BS (TL $=120-180 \mathrm{~cm} ; 48 \%$ and $50 \%$, respectively) were predominant, while in the EMED a large predominance of juveniles was observed (TL $\leq 120 \mathrm{~cm} ; 63 \%$ ). Noticeably 67\% of the BS sampled in the Ionian Sea and 95\% of those sampled in the Adriatic Sea were juveniles. Large BS are similarly represented in the geographical groups with percentages varying from 25\% (EMED) to 34\% (NA), full details presented in Table S1. 
156 A total of 207 and 170 BS individuals were sequenced for Cytb (762bp) and CR (747bp), 157 respectively. Haplotype sequences (Cytb, $\mathrm{N}=23$ and $\mathrm{CR}, \mathrm{N}=55$ ) were deposited in GenBank 158 under the Accession Numbers (available upon acceptance of the paper).

159 The Cytb sequence dataset exhibited 16 polymorphic segregating sites while CR dataset showed 16027 polymorphic segregating sites. The Cytb haplotype diversity ranged from 0.784 to 0.835 , and 161 that of the $\mathrm{CR}$ from 0.932 to 1.000 . The Cytb nucleotide diversity ranged from 0.001 to 0.002 , 162 and that of the CR from 0.004 to 0.008 . Detailed genetic diversity of BS samples collected from 163 the four macro areas and all sampling locations is presented in Table 1 and Table S2, 164 respectively.

165 The Cytb and CR haplotype networks highlighted the distribution of haplotypes irrespective of 166 the geographical origin of BS samples, indicating the lack of phylogeographical structure in the 167 Mediterranean and adjacent North Atlantic BS (see Fig. 2, Fig. S1). In the Cytb network, the four 168 main frequent haplotypes were shared by BS from all the four geographical areas, except for the 169 most frequent haplotype which was shared by BS from the three geographical areas, SNEATL, 170 WMED and EMED. In the CR network, six most frequent haplotypes ( $\mathrm{N}^{\circ}$ individuals $\geq 10$ ) were 171 observed. Although these six haplotypes were shared by all geographical areas, three of them 172 were shared by Mediterranean and SNEATL, one by Mediterranean and NNEATL, and two 173 within the Mediterranean. In both networks, most of the NNEATL haplotypes were singletons 174 (Fig. 2).

175 The AMOVA (Tab.2) revealed a significant overall $\Phi_{\mathrm{ST}}$ among population samples for both 176 markers. Significant partition of molecular variance among areas was observed when BS 177 sampling locations were grouped according to the four geographical areas in both markers 178 (AMOVA4), according to three areas (NEATL (NNEATL+SNEATL) vs WMED vs EMED; AMOVA3), and according to two areas (NEATL (NNEATL+SNEATL) vs MED 180 (WMED+EMED), for both dataset. However, the grouping that best described the partitioning of 181 genetic variance is when the different sampling locations are subdivided into four areas showing 182 the lowest partition of molecular variance among populations within group.

183 With the Cytb sequence data, all pairwise $\Phi_{\mathrm{ST}}$ values among the four geographical areas were 184 significant except that between the two Atlantic groups $\left(\Phi_{\mathrm{ST}}=0.1152 ; \mathrm{p}=0.019\right)$ that became 185 non-significant after the Bonferroni correction for multiple tests (Martin \& Douglas, 1995) (Table 186 3). Unlike the CR dataset, only the pairwise $\Phi_{\mathrm{ST}}$ values between SNEATL and the two 
187 Mediterranean areas and between WMED and EMED remained significant after the Bonferroni 188 correction for multiple tests (Table 3).

189 AMOVA and pairwise $\Phi_{\mathrm{ST}}$ analyses were performed on a reduced dataset, selecting only juvenile 190 and immature specimens from each sampling site. Despite the reduced sample sizes and the 191 complete absence of data from the site NNEATL, the results obtained are in agreement with the 192 values observed with the complete dataset (Tab. S3; S4)

193 The Cytb distribution of sequence mismatch pairwise differences showed a skewed unimodal 194 distribution in all four BS macro areas suggesting a recent bottleneck or sudden population 195 expansion (Fig. S2). A unimodal mismatch distribution was obtained with CR dataset in the 196 NNEATL BS. The CR mismatch distribution of EMED, SNEATL and NNEATL BS resulted to a 197 slightly ragged pattern (Fig. S2) that could suggest a more constant population size of the 198 Mediterranean BS over generations.

199 Both BSP analyses suggested a constant population size increase of Mediterranean and North200 eastern Atlantic BS, starting more recently in the Mediterranean than in the North-eastern 201 Atlantic ( 0.02-0.15 Mya vs 0.15-0.4 Mya; Fig. 3). Divergence time analysis based on both 202 markers (Fig. S3) highlights a similar pattern of separation between two main groups, composed 203 by BS from all regions, without any evidence of separation between defined geographic areas. 204 The separation between the two clades, which is strongly supported of Posterior Probability (PP = 205 1.0) in both markers, is dated back to 1.24 Mya and 0.94 Mya using Cytb and control region, 206 respectively.

\section{DISCUSSION AND CONCLUSIONS}

208 The BS is probably the most mobile shark species in the world (Stevens, 1990) and past research 209 works, using both mitochondrial and nuclear markers, have struggled to find genetic structure at 210 interoceanic scale (Sampaio da Costa, 2013; King et al., 2015; Li et al., 2016; Veríssimo et al., 211 2017). This high level of gene flow make it difficult to define clear BS population units. In the 212 Pacific Ocean, the lack of structure may be the result of the combination of high potential of 213 migration and the lack of effective barriers to gene flow (Veríssimo et al., 2017).

214 Experimental data have indicated that no significant genetic structure is detected in spatially 215 distant BS samples (King et al., 2015; Li et al., 2016; Veríssimo et al., 2017). Our results revealed 216 significant signals of geographical structuring for Mediterranean and adjacent Atlantic BS, with 
217 several frequent mtDNA haplotypes that are exclusive of the Mediterranean BS and other that are

218 shared with the Atlantic population samples.

219 While both haplotype networks failed to evidence a clear geographical structure, either between

220 Mediterranean and North Atlantic BS or within the Mediterranean, the results of AMOVA

221 revealed a significant partition of molecular variance among all population samples and when

222 they were grouped according to the four geographical areas with both mitochondrial markers

223 (8.87\% for Cytb and 7.93\% for CR). Previous studies carrying out AMOVA on the Atlantic BS

224 using the control region variation, showed a significance variance among groups formed by the

225 North Atlantic BS collected from Portugal and Azores and by the South African (See Table 7 of

226 Sampaio da Costa, 2013) or Brazilian BS (Veríssimo et al., 2017). On the contrary, the global

227 population genetics carried out by Fitzpatrick (2012), using concatenated fragments from: 16S,

228 tRNA, COII, ATPase and control region genes, showed no significance variation among oceans,

229 based upon comparisons between North Atlantic and all sampling locations combined (See Table

2305.7 of Fitzpatrick, 2012). Although BS exhibits high potential of dispersal and migration, our

231 results seem to reject an absence of geographical structure in the Mediterranean and adjacent

232 North-eastern Atlantic BS. The pairwise $\Phi$ st analysis revealed a geographical structuring between

233 the two Mediterranean groups and Southern North-eastern Atlantic BS, with a closer genetic

234 similarity of the Southern North-eastern Atlantic with the Western Mediterranean BS rather than

235 with the Eastern Mediterranean BS. This pattern of differentiation seems to suggest that

236 reproductive movements, such as female philopatry, may occur between the Western

237 Mediterranean and the Southern North-eastern Atlantic BS. In addition, pairwise $\Phi$ st values

238 highlighted that the EMED BS are the more divergent from the NATL BS Given that SNNEATL

239 specimens are from a previously identified nursery site (Veríssimo et al., 2017), the pairwise $\Phi_{\mathrm{ST}}$

240 values could suggest that specimens from WMED can be reproductively related to the

241 SNNEATL, while EMED could represent a nursery site in itself (Megalofonou et al., 2009).

242 Our sampling work has also preliminarily revealed significant differences between North-eastern

243 Atlantic and Mediterranean BS by sex-ratio and size. This pattern could be the result of a sex-

244 biased reproductive migratory behaviour that could contribute to explain the significant

245 phylogeographical structure. Similarly, size differences were observed between WMED and

246 EMED BS, with the large and sexually mature individuals abundant in the easternmost

247 Mediterranean sampling location (Aegean Sea) while the sub-adult and juvenile BS frequent in

248 the Adriatic and Ionian Seas. The great abundance of juvenile BS in the Adriatic Sea seemed to 
249 confirm the nursery role of this area for BS (Megalofonou et al., 2009). The biological data 250 reported in Megalofonou and colleagues (2009) describe a larger amount of big female in the 251 easternmost Mediterranean (e.g. Aegen Sea) which is in agreement with the pattern inferred from 252 our dataset. Conversely, using data on size and maturity stages, Kohler and colleagues (2002) 253 observe that the majority of sharks from the Mediterranean Sea were juvenile and immature (99\% 254 of males and $98 \%$ of females; mean $=65 \mathrm{~cm}$ of fork length). The difference may be related to the 255 different sampling design and fishing gear used in the studies. In fact, the majority of the data 256 collected by Kohler and colleagues (2002) came from volunteer recreational fishermen, while the 257 individuals from Megalofonou et al. (2009) and from this work, originated principally as by-catch 258 from commercial fisheries, such tuna and swordfish longline.

259 Overall, Mediterranean and adjacent North-eastern Atlantic BS displayed a complex geographical 260 structure in which weak but significant differences proved that a certain degree of population 261 connectivity across the Strait of Gibraltar occurred. These results are in contrast with those 262 obtained by tagging data in the past (Kohler et al., 1998; 2002; 2008; Poisson et al., 2015). 263 Similar findings of genetic differences were observed in other shark species, more related to a 264 benthic environment, such the small-spotted catshark, Scyliorhinus canicula, and the velvet belly 265 lanternshark, Etmopterus spinax (Gubili et al., 2014;2016; Kousteni et al., 2015). The reported 266 evidence of genetic structure in the blue shark analyzed in this study are associated with 267 geographical differences in sex-ratio and size. Our results suggest BS in the NE Atlantic and the 268 Mediterranean are not panmictic. There is still no direct observations of mating events take place 269 in the Eastern Mediterranean, but the biological data analysis results support the Eastern 270 Mediterranean as an important nursery area for this species (Megalofonou et al., 2009). Such 271 microevolutionary pattern of differentiation of Mediterranean and North-eastern Atlantic BS 272 prompt the need for a deeper population genetic analysis on the same population samples with 273 more powerful markers for investigating potential subtle structure of BS populations (e.g. 274 microsatellites or SNPs) to provide robust data on BS population structure that are of priority for 275 the BS stock management. High genetic diversity values are usually related to large population 276 size (Frankham, 1996), and the high genetic diversity showed by both Mediterranean and North277 eastern Atlantic BS at the two mitochondrial makers advocates in favour of a large size of these 278 populations. Mediterranean and North-eastern Atlantic BS showed higher Cytb gene 279 polymorphism than Pacific BS (Mediterranean and North-eastern Atlantic: $h=0.777-0.814 ; \pi=$ $2800.002-0.004$; Pacific: $h=0.517-0.768 ; \pi=0.0007-0.0011$, Li et al., 2016). 
281 Based on nuclear markers, similar values of observed heterozygosity were detected between 282 Pacific and North Atlantic BS (Sampaio da Costa, 2013; King et al., 2015; Veríssimo et al., 283 2017). High genetic diversity in abundant species is likely due to a combination of demographic 284 factors, such as local population sizes, fast generation times and high rates of gene flow with 285 other populations (Hague \& Routman, 2016). The high genetic diversity shown by Mediterranean 286 and North-eastern Atlantic BS could be a consequence of the short time elapsed, in proportion to 287 the relative generation time, since the population started to suffer overexploitation. In fact, the 288 abundance of the Mediterranean BS has declined by 78-90\% over the past 30 years (Ferretti et 289 al., 2008), approximately corresponding to three generations; the BS generation time was 290 estimated at 8.2 and 9.8 years for South African and North Atlantic populations, respectively 291 (Cortès et al., 2015). Furthermore, biological characters such as the large size of litters, the low 292 nucleotide substitution rate compared to other vertebrates (Martin et al., 1992), the high potential 293 of migration and the high gene flow between geographical distant populations, may have affected 294 the relationship between genetic diversity and population size, masking the sudden potential 295 population bottleneck of the last three decades, without genetic erosion.

296 Otherwise, the mismatch distributions of the different macro areas appear to be slightly skewed 297 unimodal, related to a recent bottleneck or a sudden population expansion (Fig. S2), and given 298 the Bayesian skyline plots (Fig.3), there is overwhelming evidence that the Mediterranean and 299 North East Atlantic populations have undergone a constant population expansion during the last 300 400-200 Kya, especially within the Mediterranean samples.

301 The data we show here represent a novelty for the knowledge of Mediterranean blue shark, and 302 our findings highlight the importance of the Mediterranean Sea as nursery area for this species, 303 with direct implication to specific conservation measures for the species.

304 This work sheds new light on the understudied BS of the Mediterranean Sea, and emphasizes the 305 need of conducting further population genetic surveys on this population. With ongoing efforts, 306 (i.e. https://fishreg.jrc.ec.europa.eu/web/medbluesgen/) a greater understanding of the genetic 307 diversity, spatial population structure and gene flow in this species will be achieved, which will 308 enable us to devise more effective strategies for the management of this increasingly exploited 309 ocean predator.

\section{ACKNOWLEDGEMENTS}


311 We are grateful to all MEDBLUESGEN partners that contributed to the fulfilment of project, 312 including both scientific staff and administrative colleagues. We thank Clara Hugon for the 313 valuable technical support.

314

Altschul SF, Gish W, Miller W, Myers EW, Lipman DJ. 1990. Basic local alignment search tool. Journal of Molecular Biology, 215(3):403-410 doi:https://doi.org/10.1016/S0022$\underline{2836(05) 80360-2}$

Chen X, Xiang D, Ai W, Shi X. 2013. Complete mitochondrial genome of the blue shark Prionace glauca (Elasmobranchii: Carcharhiniformes). Mitochondrial DNA, 26(2):313314 doi: 10.3109/19401736.2013.825790

Clarke SC, McAllister MK, Milner-Gulland EJ, Kirkwood GP, Michielsens CGJ, Agnew DJ, Pikitch EK, Nakano H, Shivji MS. 2006. Global estimates of shark catches using trade records from commercial markets. Ecology Letters, 9(19): 1115-1126 doi:10.1111/j.1461$\underline{0248.2006 .00968 . x}$

Coelho R, Mejuto J, Domingo A, Yokawa K, Liu K-M, Cortés E, Romanov EV,| Da Silva C, Hazin F, Arocha F, Mwilima AM, Bach P, De Zárate VO, Roche W, Lino PG, GarcíaCortés B, Ramos-Cartelle AM,Forselledo R, Mas F, Ohshimo S, Courtney D, Sabarros PS, Perez B,Wogerbauer C,Tsai W-P, Carvalho F, Santos MN. 2017. Distribution patterns and population structure of the blue shark (Prionace glauca) in the Atlantic and Indian Oceans. Fish and Fisheries, 2017:1-17 doi: 10.1111/faf.12238

Compagno LJV. 1984. FAO Species Catalogue. Vol 4: Sharks of the world, Part 2 Carcharhiniformes. FAO Fisheries Synopsis No. 125 4(2): 251-633

Cortés E, Domingo A, Miller P, Forselledo R, Mas F, Arocha F, Campana S, Coelho R, Da Silva C, Hazin FHV, Holtzhausen H, Keene K, Lucena F, Ramirez K, Santos MN, SembaMurakami Y, Yokawa K. 2015. Expanded ecological risk assessment of pelagic sharks caught in Atlantic pelagic longline fisheries. Collective Volume of Scientific Papers ICCAT, 71(6): 2637-2688 SCRS/2012/167

Darriba D, Taboada GL, Doallo R, Posada D. 2012. jModelTest 2: more models, new heuristics and parallel computing. Nature Methods, 9(8)772 doi:10.1038/nmeth.2109 
340

341

Drummond AJ, Rambaut A, Shapiro B, Pybus OG. 2005 Bayesian Coalescent Inference of Past Population Dynamics from Molecular Sequences. Mol Biol Evol, 22(5): 1185-1192 doi: https://doi.org $/ 10.1093 / \mathrm{molbev} / \mathrm{msi103}$

Drummond AJ, Suchard MA, Dong Xie, Rambaut A. 2012. Bayesian phylogenetics with BEAUti and BEAST 1.7. Molecular Biology and Evolution, 29(8):1969-1973 doi:10.1093/molbev/mss075

Dulvy NK, Fowler SL, Musick JA, Cavanagh RD, Kyne PM, Harrison RL, Carlson JK, Davidson LNK, Fordham SV, Francis MP, Pollock CM, Simpfendorfer CA, Burgess GH, Carpenter KE, Compagno LJV, Ebert DA, Gibson C, Heupel MR, Livingstone SR, Sanciangco JC, Stevens JD, Valenti S, White WT. 2014. Extinction risk and conservation of the world's sharks and rays. eLife, 3: e00590 doi: http://dx.doi.org/10.7554/eLife.00590.001

Excoffier L, Lischer HE. 2010. Arlequin suite ver3.5: a new series of programs to perform population genetics analyses under Linux and Windows. Molecular Ecology Resources, 10(3):564-567 doi:10.1111/j.1755-0998.2010.02847.x

Excoffier L, Smouse P, Quattro J. 1992. Analysis of molecular variance inferred from metric distances among DNA haplotypes: application to human mitochondrial DNA restriction data. Genetics, 131:479-491

Felsenstein J. 2005. "PHYLIP (phylogeny inference package)" Distributed by the author. Department of Genome Sciences, University of Washington, Seattle), Version 3 (http://evolution.genetics.washington.edu/phylip.html)

Felsenstein, J. 1989. PHYLIP -Phylogeny Inference Package (Version 3.2). Cladistics, 5: 164-166 Ferretti F, Myers RA, Serena F, Lotze HK. 2008. Loss of Large Predatory Sharks from the Mediterranean Sea. Conservation Biology, 22(4): 952-964 doi:10.1111/j.15231739.2008.00938.x

Fitzpatrick SF. 2012. Global population genetic structure of the pelagic blue shark (Prionace glauca). PhD Thesis, Queen's University Belfast

Fowler SL, Cavanagh RD, Camhi M, Burgess GH, Cailliet GM, Fordham SV, Simpfendorfer CA, Musick JA. 2005. Sharks, Rays and Chimaeras: The Status of the Chondrichthyan Fishes. Status Survey. IUCN/SSC Shark Specialist Group. IUCN, Gland, Switzerland and Cambridge, UK. 461 pp

Frankham R. 1996. Relationship of Genetic Variation to Population Size in Wildlife. Conservation Biology, 10(6):1500-1508 
372 Gubili C, Macleod K, Perry W, Hanel P, Batzakas I, Farrell ED, Lynghammar A, Mancusi C,

373

374

375

376

Mariani S, Menezes GM, Neat F, Scarcella G, Griffiths AM. 2016. Connectivityinthedeep:Phylogeographyofthevelvetbelly lanternshark. Deep Sea Research Part I Oceanographic Research Papers, 115: 233-239 doi:https://doi.org/10.1016/j.dsr.2016.07.002

Gubili C, Sims DW, Veríssimo A, Domenici P, Ellis J, Grigoriou P, Johnson AF, McHugh M, Neat F, Satta A, Scarcella G, Serra-Pereira B, Soldo A, Genner MJ, Griffiths AM. 2014. A tale of two seas: contrasting patterns of population structure in the small-spotted catshark across Europe. Royal Society Open Science, 1: 140175 doi:http://dx.doi.org/10.1098/rsos.140175

Hague MTJ, Routman EJ. 2016. Does population size affect genetic diversity? A test with sympatric lizard species. Heredity, 116:92-98 doi:10.1038/hdy.2015.76

ICCAT (International Commission for the Conservation of Atlantic Tunas). 2015a. Report of the 2015 ICCAT Blue Shark stock assessment session. Lisbon, Portugal. SCRS/P/2015/031

King JR, Wetklo M, Supernault J, Taguchi M, Yokawa K, Sosa-Nishizaki O, Withler RE. 2015. Genetic analysis of stock structure of blue shark (Prionace glauca) in the north Pacific ocean. Fisheries Research, 172: 181-189 doi: http://doi.org/10.1016/j.fishres.2015.06.029

Kohler NE, Turner P. 2008. Stock structure of the blue shark (Prionace glauca) in the North Atlantic Ocean based on tagging data. Sharks of the Open Ocean: Biology, Fisheries and Conservation: 339-350. Blackwell Publishing Ltd

Kohler NE, Turner PA, Hoey JJ, Natanson LJ, Briggs R. 2002. Tag and recapture data for three pelagic shark species: blue shark (Prionace glauca), shortfin mako (Isurus oxyrinchus) and porbeagle (Lamna nasus) in the North Atlantic Ocean. International Commission for the Conservation of Atlantic Tunas, Collective Volume of Scientific Papers SCRS/2001/64, 54(4): 1231-1260

Kohler NE, Casey JG, Turner PA. 1998. NMFS Cooperative Shark Tagging Program, 1962-93: An Atlas of Shark Tag and Recapture Data. Marine Fisheries Review, 60(2):1-87

Kousteni V, Kasapidis P, Kotoulas G, Megalofonou P. 2015. Strong population genetic structure and contrasting demographic histories for the small-spotted catshark (Scyliorhinus canicula) in the Mediterranean Sea. Heredity, 114: 333-343. doi:10.1038/hdy.2014.107

Li W, Dai X, Zhu J, Tian S, He S, Wu F. 2016. Genetic differentiation in blue shark, Prionace glauca, from the central Pacific Ocean, as inferred by mitochondrial cytochrome b region. Mitochondrial DNA Part A, 19:1-4 doi: 10.3109/19401736.2015.1137903 
405 Librado P, Rozas J. 2009. DnaSP v5: a software for comprehensive analysis of DNA

406

407

408

409

410

411

412

413 polymorphism

data.

Bioinformatics

25(11):

1451-1452

Martin AP, Naylor GJP, Palumbi SR. 1992. Rates of mitochondrial DNA evolution in sharks are slow compared with mammals. Nature, 357:153-157 doi:10.1038/357153a0

Martin AP, Palumbi SR. 1993.Body size, metabolic rate, generation time, and the molecular clock. Proceedings of the National Academy of Sciences USA 90(9): 4087-4091 doi: $\underline{10.1073 / \text { pnas.90.9.4087 }}$

Martin BJ, Douglas GA. 1995. Multiple significance tests: the Bonferroni method. British Medical Journal, 310(21):170 doi:http://dx.doi.org/10.1136/bmj.310.6973.170

Megalofonou P, Damalas D, De Metrio G. 2009. Biological characteristics of blue shark, Prionace glauca, in the Mediterranean Sea. Journal of the Marine Biological Association of the United Kingdom, 89(06): 1233-1242 doi:10.1017/S0025315409000216

Megalofonou P, Damalas D, Yannopolous C. 2005. Composition and abundance of pelagic shark by-catch in the eastern Mediterranean Sea. Cybium 29(2):135-140

Mourier J, Planes S. 2013. Direct genetic evidence for reproductive philopatry and associated fine-scale migrations in female blacktip reef sharks (Carcharhinus melanopterus) in French Polynesia. Molecular Ecology, 22: 201-214 doi:10.1111/mec.12103

Ovenden JR, Kashiwagi T, Broderick D, Giles J,Salini J. 2009. The extent of population genetic subdivision differs among four co-distributed shark species in the Indo-Australian archipelago. BMC Evolutionary Biology, 9:40 doi:10.1186/1471-2148-9-40

Poisson F, Mitsunaga Y, Kojima T, Torisawa S, Seret B, Demarcq H, Banegue A, Groul Jm. 2015. Satellite Tagging of Blue Sharks (Prionace glauca) in the Gulf of Lions: depth behaviour, temperature experience and movements - Preliminary results. In: Marine Productivity: perturbations and resilience of socio-ecosystems. Proceedings of the 15th FrenchJapanese Oceanography Symposium Editors: Hubert-Jean Ceccaldi, Yves Hénocque, Yasuyuki Koike, Teruhisa Komatsu, Georges Stora, Marie-Hélène Tusseau-Vuillemin. Part VIII Short and Preliminary Communications, pp.367-368. doi: https://doi.org/10.1007/978-3-319-13878-7_41

Pratt HL. 1979. Reproduction in the Blue Shark, Prionace glauca. Fishery Bulletin 77(2): 445470. 
436 Sampaio da Costa IRF. 2013. Genetic Diversity and Population Structure of the Cosmopolitan

Blue Shark Prionace glauca (Linnaeus, 1758 ) in the Atlantic Ocean. MSc Thesis, Centro de Investigação em Biodiversidade e Recursos Genéticos (CIBIO), University of Porto

Sims D, Fowler SL, Ferretti F, Stevens JD. 2016. Prionace glauca. The IUCN Red List of Threatened Species 2016: e.T39381A16553182

Stevens J. 2009. Prionace glauca. The IUCN Red List of Threatened Species 2009: e.T39381A10222811 http://dx.doi.org/10.2305/IUCN.UK.20092.RLTS.T39381A10222811.en.

Stevens JD. 1990. Further results from a tagging study of pelagic sharks in the north-east Atlantic. Journal of the Marine Biological Association of the United Kingdom, 70(4):

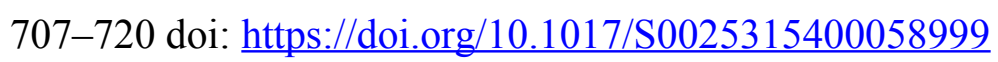

Tamura K, Stecher G, Peterson D, Stecher G, Filipski A, Kumar S. 2013. MEGA6: Molecular Evolutionary Genetics Analysis version 6.0. Molecular biology and evolution. 30(12): 2725-2729 doi:https://doi.org/10.1093/molbev/mst197

Tillett BJ, Meekan MG, Field IC, Thorburn DC, Ovenden JR. 2012. Evidence for reproductive philopatry in the bull shark Carcharhinus leucas. Journal of Fish Biology, 80: 2140-2158 doi:10.1111/j.1095-8649.2012.03228.X

Untergasser A, Cutcutache I, Koressaar T, Ye J, Faircloth BC, Remm M, Rozen SG. 2012. Primer3 - new capabilities and interfaces. Nucleic Acids Research 40(15):e115 doi:https://doi.org/10.1093/nar/gks596

Vandeperre F, Aires-da-Silva A, Fontes J, Santos M, Serrão Santos R, Afonso P. 2014. Movements of blue sharks (Prionace glauca) across their life history. PLoS ONE 9(8): e103538 doi: https://doi.org/10.1371/journal.pone.0103538

Veríssimo A, Sampaio Í, McDowell JR, Alexandrino P, Mucientes G, Queiroz N, Da Silva C, Jones CS, Noble LR. 2017. World without borders-genetic population structure of a highly migratory marine predator, the blue shark (Prionace glauca). Ecology and Evolution. 7(13): 4768-4781 doi: 10.1002/ece3.2987 
Figure 1

Sampling sites of Mediterranean and North Eastern Atlantic Blue Sharks.

North North-Eastern Atlantic (NNEATL, red dots, $\mathrm{N}=16$ ), South North-Eastern Atlantic (SNEATL, blue dots, $\mathrm{N}=33$ ), Western Mediterranean (WMED, purple dots, $\mathrm{N}=109$ ) and Eastern Mediterranean (EMED, green dots, $\mathrm{N}=56$ ). The map was created using $\mathrm{R}$ version 3.4.1 ("R: $\mathrm{A}$ Language and Environment for Statistical Computing, R Core Team, R Foundation for Statistical Computing, Vienna, Austria (2016) https://www.R-project.org"). Original S code by Richard A. Becker, Allan R. Wilks. R version by Ray Brownrigg. Enhancements by Thomas P Minka and Alex Deckmyn. (2017). maps: Draw Geographical Maps. R package version 3.2.0. https://CRAN.R-project.org/package=maps.

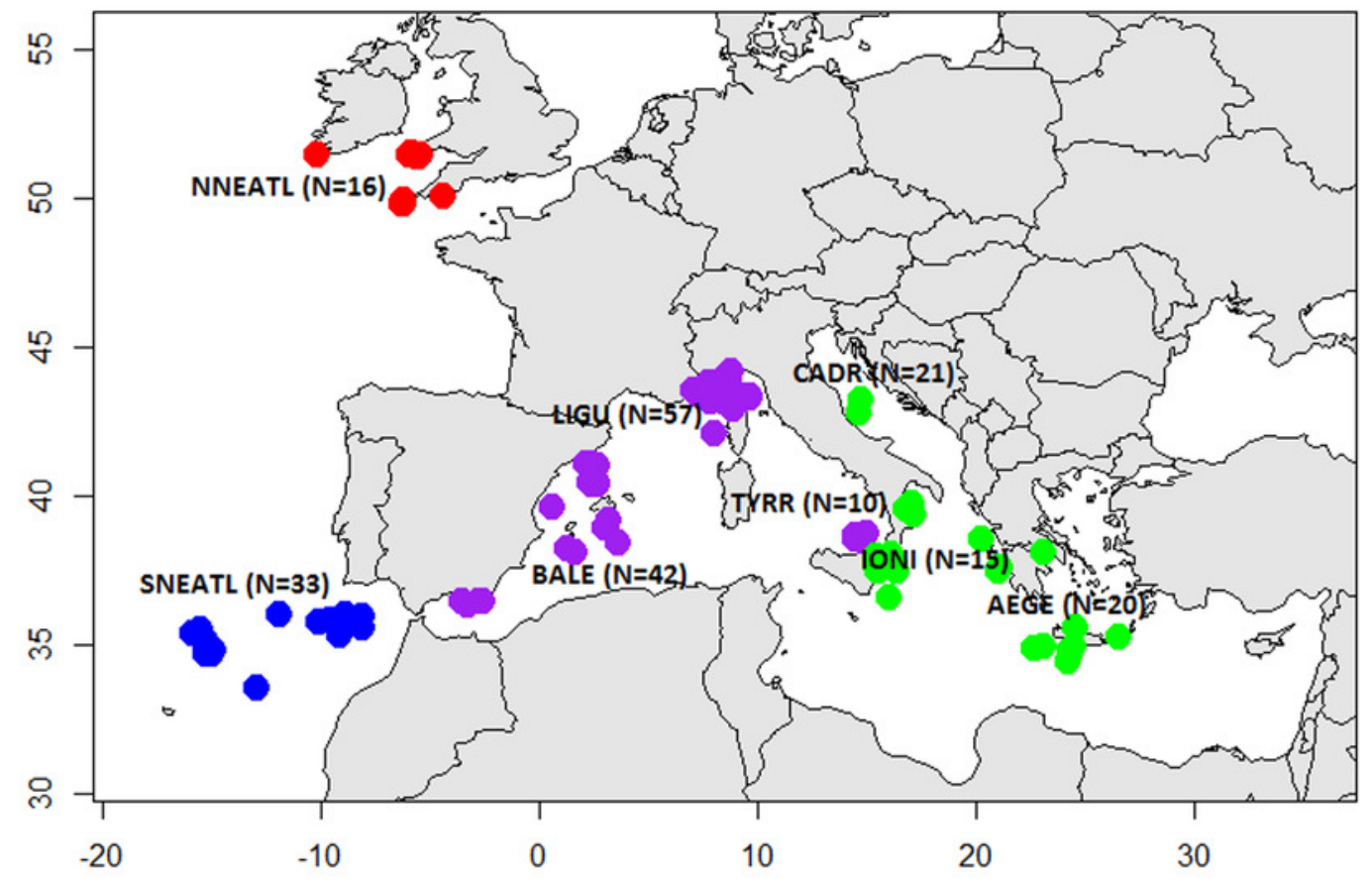




\section{Figure 2}

Cytochrome-b (A) and Control Region (B) Maximum Likelihood Haplotype Network of Mediterranean/North East Atlantic Blue Shark collected from the four geographical areas.

NNEATL: North North-Eastern Atlantic; SNEATL: South North-Eastern Atlantic; WMED: Western Mediterranean; EMED: Eastern Mediterranean.

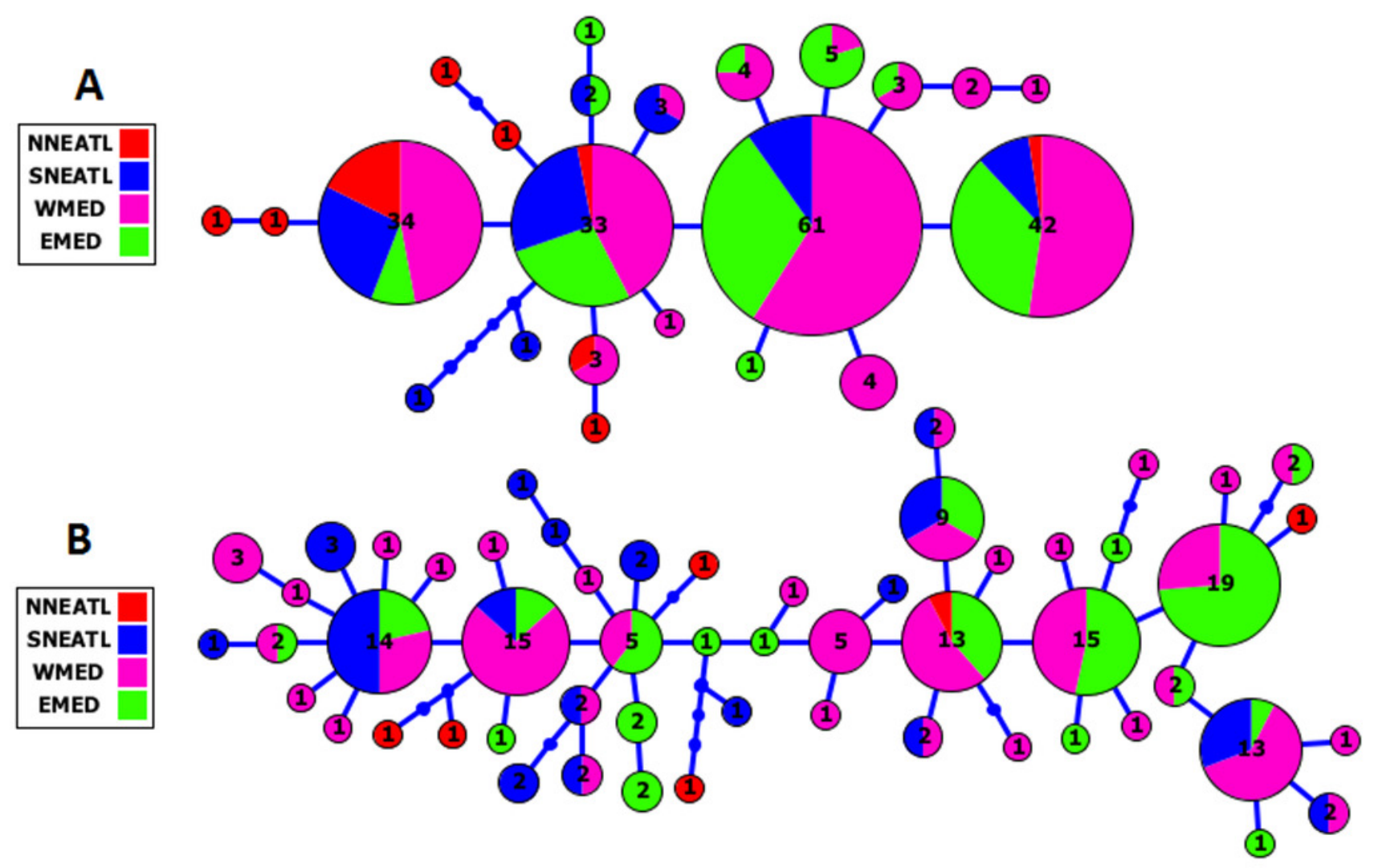




\section{Figure 3}

Bayesian Skyline Plot from the Cytb, A-D, and control region, E-H, of the four different geographical areas.

NNEATL: North North-eastern Atlantic; SNEATL: South North-eastern Atlantic; WMED: Western Mediterranean; EMED: Eastern Mediterranean. The Y-axis indicates effective population size $(\mathrm{Ne}) \mathrm{x}$ generation time, while the $\mathrm{X}$-axis indicates mean time in thousands of years before present. The thick line represents the average, while the blue band represents $95 \%$ highest posterior density (HPD) intervals. 

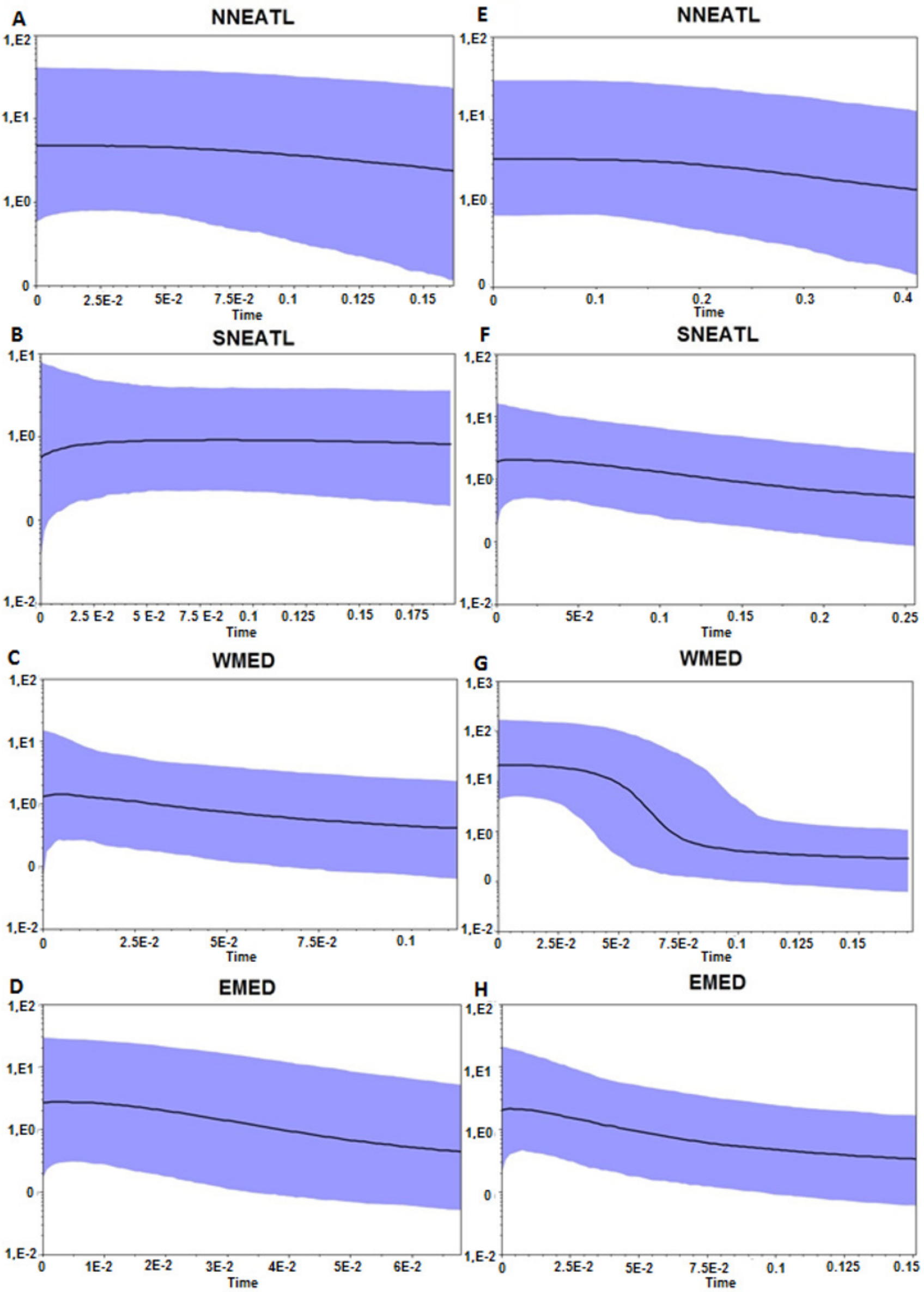

Peer) reviewing PDF | (2017:08:19869:1:1:NEW 31 Oct 2017) 


\section{Table $\mathbf{1}$ (on next page)}

Mitochondrial gene polymorphism of Prionace glauca population samples subdivided according to the four macro areas.

$\mathrm{N}$, number of individuals; Nh, number of haplotypes; S, Number of segregating informative sites; $h$, haplotype diversity and associate standard deviation; $\pi$, nucleotide diversity and associate standard deviation. NNEATL: North North-eastern Atlantic; SNEATL: South Northeastern Atlantic; WMED: Western Mediterranean; EMED: Eastern Mediterranean. 
1

2 Cytb

\begin{tabular}{cccccccc}
\hline POP & $N$ & $N h$ & $S$ & $h$ & stdev $h$ & $\pi$ & stdev $\pi$ \\
\hline NNEATL & 14 & 9 & 6 & 0.835 & 0.010 & 0.00231 & 0.00046 \\
SNEATL & 33 & 8 & 10 & 0.822 & 0.034 & 0.00200 & 0.00038 \\
WMED & 105 & 13 & 6 & 0.801 & 0.023 & 0.00167 & 0.00011 \\
EMED & 55 & 10 & 6 & 0.784 & 0.033 & 0.00151 & 0.00013 \\
TOTAL & 207 & 23 & 16 & 0.821 & 0.013 & 0.00184 & 0.00010 \\
\hline
\end{tabular}

CR

\begin{tabular}{cccccccc}
\hline POP & $N$ & $N h$ & $S$ & $h$ & stdev $h$ & $\pi$ & stdev $\pi$ \\
\hline NNEATL & 6 & 6 & 15 & 1.000 & 0.093 & 0.00812 & 0.00106 \\
SNEATL & 33 & 17 & 13 & 0.932 & 0.026 & 0.00424 & 0.00038 \\
WMED & 79 & 34 & 18 & 0.949 & 0.011 & 0.00418 & 0.00019 \\
EMED & 52 & 19 & 12 & 0.894 & 0.028 & 0.00382 & 0.00031 \\
TOTAL & 170 & 55 & 27 & 0.951 & 0.006 & 0.00453 & 0.00014 \\
\hline
\end{tabular}

3

4 


\section{Table 2 (on next page)}

Analysis of molecular variance (AMOVA) of Cytochrome b (Cytb) and Control Region (CR) of the Mediterranean and North-eastern Atlantic Blue Sharks ( Prionace glauca). 
1

\begin{tabular}{|c|c|c|c|c|c|c|}
\hline & Cytb & & & $\mathrm{CR}$ & & \\
\hline & $\%$ variation & $\Phi$-Statistics & $\mathrm{p}$ & $\%$ variation & $\Phi$-Statistics & $p$ \\
\hline \multicolumn{7}{|l|}{$\begin{array}{l}\text { AMOVA1: Overall } \\
\text { (all population samples) }\end{array}$} \\
\hline Among populations & 8.20 & & & 11.25 & & \\
\hline Within populations & 91.80 & $\mathrm{ST}=0.0819$ & 0.00000 & 88.75 & $\mathrm{ST}=0.11249$ & 0.00000 \\
\hline \multicolumn{7}{|c|}{$\begin{array}{l}\text { AMOVA2: } 2 \text { groups: } \\
\text { (NNEATL+SNEATL vs WMED+EMED) }\end{array}$} \\
\hline Among groups & 12.39 & $\mathrm{CT}=0.1239$ & 0.03496 & 7.89 & $\mathrm{CT}=0.0788$ & 0.03471 \\
\hline Among pops within group & 2.40 & $S C=0.0273$ & 0.02287 & 7.41 & $S C==0.0804$ & 0.00005 \\
\hline Within populations & 92.68 & ST $=0.1479$ & 0.00000 & 84.70 & $\mathrm{ST}=0.1529$ & 0.00000 \\
\hline \multicolumn{7}{|c|}{$\begin{array}{l}\text { AMOVA3: } 3 \text { groups: } \\
\text { (NNEATL+SNEATL vs WMED vs EMED) }\end{array}$} \\
\hline Among groups & 7.01 & $\mathrm{CT}=0.0701$ & 0.02188 & 5.68 & $\mathrm{CT}=0.0568$ & 0.03656 \\
\hline Among pops within group & 2.84 & $S C=0.0305$ & 0.02397 & 6.78 & $S C=0.0719$ & 0.00075 \\
\hline Within populations & 90.15 & ST $=0.0985$ & 0.00000 & 87.54 & $\mathrm{ST}=0.1246$ & 0.00000 \\
\hline \multicolumn{7}{|c|}{$\begin{array}{l}\text { AMOVA4: } 4 \text { groups: } \\
\text { (NNEATL vs SNEATL vs WMED vs EMED) }\end{array}$} \\
\hline Among groups & 8.87 & $\mathrm{CT}=0.0887$ & 0.02073 & 7.93 & $\mathrm{CT}=0.0793$ & 0.03726 \\
\hline Among pops within group & 1.20 & $S C=0.0132$ & 0.13076 & 4.89 & $S C=0.0531$ & 0.00649 \\
\hline Within populations & 89.92 & $\mathrm{ST}=0.1007$ & 0.00000 & 87.18 & $\mathrm{ST}=0.1282$ & 0.00000 \\
\hline
\end{tabular}




\section{Table 3(on next page)}

Pairwise $\Phi$ st values (below the diagonal) and associated p-values (above the diagonal) among the blue sharks of the four geographical areas.

*Values that resulted not significant after the Bonferroni correction for multiple tests (a-level of significance after Bonferonni correction: $p=0.0083$ ). 
1

\begin{tabular}{lllll}
\hline Cytb & NNEATL & SNEATL & WMED & EMED \\
\hline NNEATL & & $0.01868^{*}$ & 0.00000 & 0.00000 \\
SNEATL & $0.08167^{*}$ & & 0.00055 & 0.00015 \\
WMED & 0.23969 & 0.08633 & & 0.20052 \\
EMED & 0.29481 & 0.12441 & 0.00658 & \\
\hline
\end{tabular}

\begin{tabular}{lllll}
\hline CR & NNEATL & SNEATL & WMED & EMED \\
\hline NNEATL & & $0.0097^{*}$ & $0.0482^{*}$ & $0.0187^{*}$ \\
SNEATL & $0.1649^{*}$ & & 0.0003 & 0.0000 \\
WMED & $0.1061^{*}$ & 0.1049 & & 0.0072 \\
EMED & $0.1620^{*}$ & 0.2188 & 0.0463 & \\
\hline
\end{tabular}

2

3 
